\title{
Adaptive Backstepping Current Control of Active Power Filter Using Neural Compensator
}

\author{
Yunmei Fang and Juntao Fei \\ College of Mechanical and Electrical Engineering, Hohai University, Changzhou 213022, China \\ Correspondence should be addressed to Juntao Fei; jtfei@yahoo.com
}

Received 16 March 2019; Revised 10 April 2019; Accepted 24 April 2019; Published 16 May 2019

Academic Editor: Javier Moreno-Valenzuela

Copyright (C) 2019 Yunmei Fang and Juntao Fei. This is an open access article distributed under the Creative Commons Attribution License, which permits unrestricted use, distribution, and reproduction in any medium, provided the original work is properly cited.

\begin{abstract}
A backstepping-based adaptive controller with neural compensator is designed for harmonic suppression in a three-phase active power filter (APF). The fundamental rule of backstepping method is to take some state variables as "virtual controls" and then design intermediate controller. An adaptive neural controller using radial basis function (RBF) is derived to estimate the APF system nonlinearity and strengthen the current's tracking property and power grid quality. Simulations studies indicate the proposed backstepping-based adaptive neural controller has good current tracking behavior and increased power quality.
\end{abstract}

\section{Introduction}

The harmonic distortion of power grid quality is becoming a serious issue with the increasing nonlinear loads in electrical equipment and power systems. Shunt active power filters (SAPF) become the main harmonic treatment way because they can effectively reduce current harmonic distortion and reactive power.

The active power filter (APF) is an intelligent harmonic control device, which detects harmonics and injects compensation current into the grid to improve power quality. There are some current controllers, i.e., hysteresis current control, triangular wave modulation control, and space vector modulation control. With the introduction of the smart grid concept, the control algorithms can achieve more accurate harmonic current tracking control effects. Yue et al. [1] designed a predictive double loop controller in order to increase the robustness and adaptive property of an active filter. Swain et al. [2] improved the robustness and stability of APF with a novel sliding controller. Intelligent control methods were developed in [3-5] to remove the current with harmonics and increase the power grid quality. Carpinelli et al. [6] adopted a multiobjective method in a multiconverter distribution system. Tareen et al. [7] decreased the power switches and improved the properties of grid-connected inverters by reducing the cost, weight, and size.
In the nonlinear systems, unknown nonlinearities can be approximated by intelligent methods such as neural networks [8] and fuzzy systems [9]. Liu et al. [10] derived an adaptive fuzzy controller with output feedback for full state constrained nonlinear systems. Wu et al. [11] proposed mixed fuzzy/boundary schemes for nonlinear parabolic PDE systems. Li et al. [12] developed a novel adaptive neural strategy with prescribed property for nonlinear systems with switched and interconnected uncertainties. Peng et al. [13] designed a novel dynamic surface controller with neural network based on a predictor for nonlinear system with uncertainty. Wang et al. [14-16] developed neural and fuzzy controllers for nonlinear systems with unknown nonlinearities. $\mathrm{Xu}$ et al. [17] derived and applied composite neural control strategy to hypersonic flight dynamics. Chen et al. [18] designed a novel intelligent sliding controller with dynamic structure using fuzzy neural controller. Wai et al. [19] designed a fuzzy-neural sliding controller to deal with the chattering.

Backstepping controller can obtain the targets of tracking and stabilization because it is a controller with recursive property, dividing a full system into lower order systems. It can relax the matching condition in the strict feedback system and avoid cancelling the useful existing nonlinearities. The fundamental idea of backstepping is to recursively derive a controller and step back from the subsystem progressively, ensuring stability for each step, until getting to the final step. 


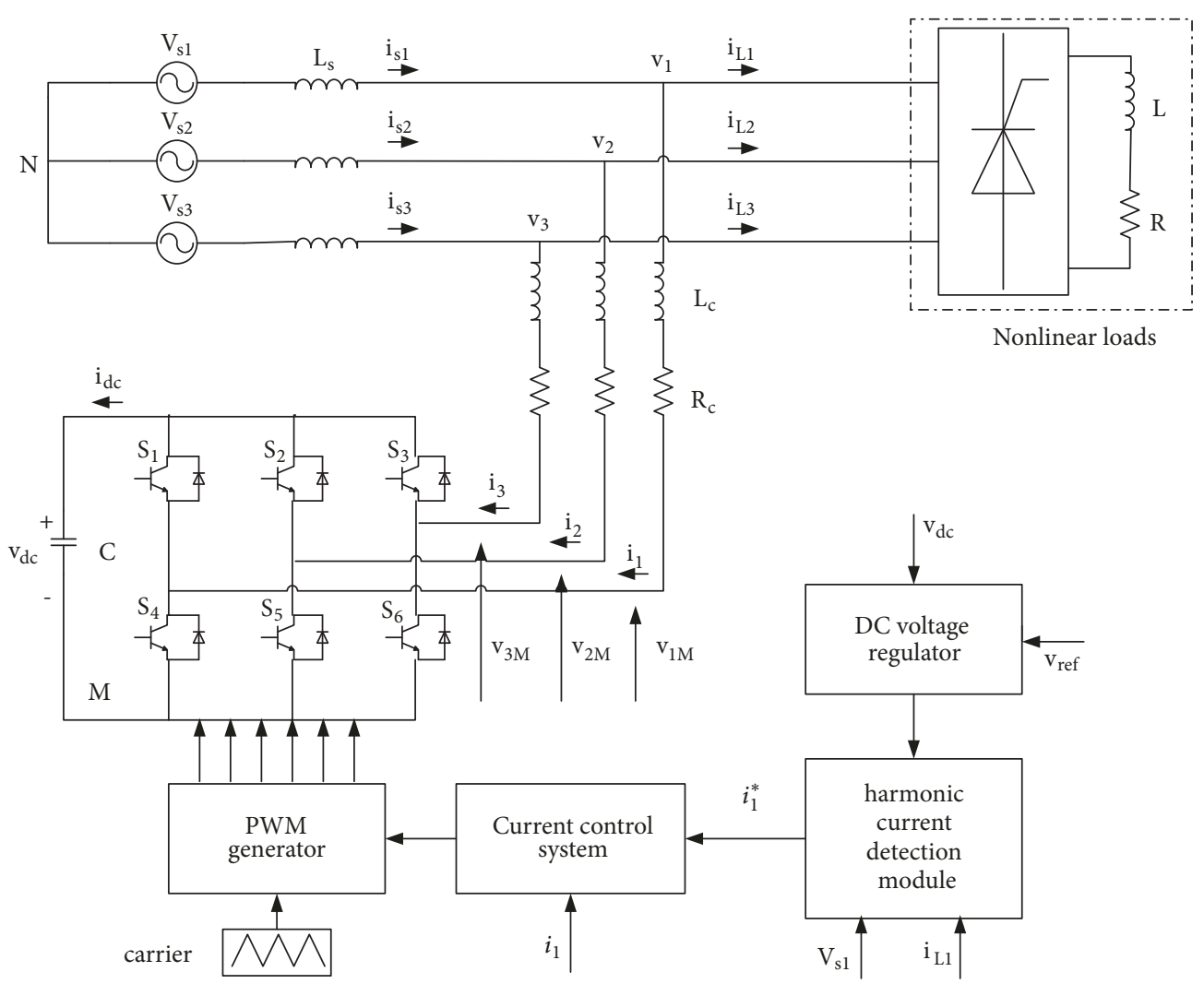

FIgURE 1: Block diagram of APF.

Thus, adaptive control is combined with neural control and backstepping approach for dynamic systems [20, 21].

Adaptive neural controller was put forward to treat the harmonics in APF and improve the power grid quality in [2224]. In this work, an adaptive neural backstepping scheme is designed to guarantee the current tracking and improve the system robustness. The innovative points can be listed as follows:

(1) A backstepping method is incorporated with the adaptive neural control to obtain the desired harmonic suppression related to the current in power grid system. The adaptive neural backstepping controller is used to compensate the nonlinear loads and increase the current tracking property and total harmonic distortion (THD) index.

(2) This control method is realized by neural controller without known accurate model of APF, making the controller simpler and easier to be achieved, strengthening the power supply quality. A robust current compensation controller is added to solve the nonzero issue with respect to the approximation errors existing in the neural system.

\section{System Description}

The schematic diagram of a three-phase shunt APF discussed in this paper is depicted in Figure 1. The main components are nonlinear loads, source and PWM generator, control system, and harmonic current detector module. The control system aimed to stabilize DC link voltage according to a basic value and track the instruction current so as to generate the compensating current to decrease the distortion current caused by nonlinear loads. In Figure $1, v_{s 1}, v_{s 2}$, and $v_{s 3}$ represent the voltages in the grid, $i_{s 1}, i_{s 2}$, and $i_{s 3}$ represent the power currents, $i_{L 1}, i_{L 2}$, and $i_{L 3}$ represent the loading currents, $v_{1}, v_{2}$, and $v_{3}$ represent the voltages in the public joint points, $i_{1}, i_{2}$, and $i_{3}$ represent the compensating current, $C$ is the capacitor in the DC side, $v_{d c}$ is the voltage in the capacitance $\mathrm{C}, i_{d c}$ is the current in the capacitance $\mathrm{C}, L_{c}$ is the inductance in the $\mathrm{AC}$ side, and $R_{c}$ denotes the equivalent resistance.

The model of an APF system is derived in the next procedure. The circuit relationships

$$
\begin{aligned}
& v_{1}=L_{c} \frac{d i_{1}}{d t}+R_{c} i_{1}+v_{1 M}+v_{M N} \\
& v_{2}=L_{c} \frac{d i_{2}}{d t}+R_{c} i_{2}+v_{2 M}+v_{M N} \\
& v_{3}=L_{c} \frac{d i_{3}}{d t}+R_{c} i_{3}+v_{3 M}+v_{M N}
\end{aligned}
$$

are obtained by Kirchhoff rules [3], where $v_{M N}$ is the voltage between $M$ and $N$.

Assuming the balanced AC supply voltage, and summing equations in (1), considering the absence of the zero-sequence yield

$$
v_{M N}=-\frac{1}{3} \sum_{m=1}^{3} v_{m M} .
$$


To indicate the IGBT working status, switch function $c_{k}$ is defined as

$$
c_{k}= \begin{cases}1, & \text { if } S_{k} \text { is On and } S_{k+3} \text { is Off } \\ 0, & \text { if } S_{k} \text { is Off and } S_{k+3} \text { is On, }\end{cases}
$$

where $k=1,2,3$.

In the meantime, considering $v_{k m}=c_{k} v_{d c}$, thus (1) is expressed as

$$
\begin{aligned}
& \frac{d i_{1}}{d t}=-\frac{R_{c}}{L_{c}} i_{1}+\frac{v_{1}}{L_{c}}-\frac{v_{d c}}{L_{c}}\left(\mathrm{c}_{1}-\frac{1}{3} \sum_{m=1}^{3} c_{m}\right) \\
& \frac{d i_{2}}{d t}=-\frac{R_{c}}{L_{c}} i_{2}+\frac{v_{2}}{L_{c}}-\frac{v_{d c}}{L_{c}}\left(c_{2}-\frac{1}{3} \sum_{m=1}^{3} c_{m}\right) \\
& \frac{d i_{3}}{d t}=-\frac{R_{c}}{L_{c}} i_{3}+\frac{v_{3}}{L_{c}}-\frac{v_{d c}}{L_{c}}\left(c_{3}-\frac{1}{3} \sum_{m=1}^{3} c_{m}\right) .
\end{aligned}
$$

Denote the switching state as

$$
d_{n k}=\left(c_{k}-\frac{1}{3} \sum_{m=1}^{3} c_{m}\right)_{n}
$$

Equation (5) shows the relation between $d_{n k}$ and $c_{k}$; then, (5) with the consideration of eight permissible IGBT switching states generates

$$
\left[\begin{array}{l}
d_{n 1} \\
d_{n 2} \\
d_{n 3}
\end{array}\right]=\frac{1}{3}\left[\begin{array}{ccc}
2 & -1 & -1 \\
-1 & 2 & -1 \\
-1 & -1 & 2
\end{array}\right]\left[\begin{array}{l}
c_{1} \\
c_{2} \\
c_{3}
\end{array}\right] .
$$

Then, (4) can be written in simplified form as

$$
\begin{aligned}
& \frac{d i_{1}}{d t}=-\frac{R_{c}}{L_{c}} i_{1}+\frac{v_{1}}{L_{c}}-\frac{v_{d c}}{L_{c}} d_{n 1} \\
& \frac{d i_{2}}{d t}=-\frac{R_{c}}{L_{c}} i_{2}+\frac{v_{2}}{L_{c}}-\frac{v_{d c}}{L_{c}} d_{n 2} \\
& \frac{d i_{3}}{d t}=-\frac{R_{c}}{L_{c}} i_{3}+\frac{v_{3}}{L_{c}}-\frac{v_{d c}}{L_{c}} d_{n 3} .
\end{aligned}
$$

Define two state variables

$$
\begin{aligned}
& x_{1}=i_{k} \\
& x_{2}=\dot{x}_{1}=\dot{i}_{k} .
\end{aligned}
$$

Differentiating $x_{1}$ and $x_{2}$ with respect to time yields

$$
\begin{aligned}
\dot{x}_{1}= & \dot{i}_{k}=-\frac{R_{c}}{L_{c}} i_{k}+\frac{v_{k}}{L_{c}}-\frac{v_{d c}}{L_{c}} d_{n k} \\
\dot{x}_{2}= & \ddot{i}_{k}=\frac{d\left(-\left(R_{c} / L_{c}\right) i_{k}+v_{k} / L_{c}-\left(v_{d c} / L_{c}\right) d_{n k}\right)}{d t} \\
= & -\frac{R_{c}}{L_{c}} \dot{i}_{k}+\frac{1}{L_{c}} \frac{d v_{k}}{d t}-\frac{1}{L_{c}} \frac{d v_{d c}}{d t} d_{n k} \\
= & \frac{R_{c}^{2}}{L_{c}^{2}} i_{k}-\frac{R_{c}}{L_{c}^{2}} v_{k}+\frac{1}{L_{c}} \frac{d v_{k}}{d t} \\
& +\left(\frac{R_{c}}{L_{c}^{2}} v_{d c}-\frac{1}{L_{c}} \frac{d v_{d c}}{d t}\right) d_{n k} .
\end{aligned}
$$

Considering the external disturbances, the model of the APF system is rewritten as

$$
\begin{aligned}
\dot{x}_{1}= & x_{2} \\
\dot{x}_{2}= & \frac{R_{c}^{2}}{L_{c}^{2}} i_{k}-\frac{R_{c}}{L_{c}^{2}} v_{k}+\frac{1}{L_{c}} \frac{d v_{k}}{d t}+u\left(\frac{R_{c}}{L_{c}^{2}} v_{d c}-\frac{1}{L_{c}} \frac{d v_{d c}}{d t}\right) \\
& +f_{d}=f(x)+b u+f_{d},
\end{aligned}
$$

where $f(x)=\left(R_{c}^{2} / L_{c}^{2}\right) i_{k}-\left(R_{c} / L_{c}^{2}\right) v_{k}+\left(1 / L_{c}\right)\left(d v_{k} / d t\right), b=$ $\left(R_{c} / L_{c}^{2}\right) v_{d c}-\left(1 / L_{c}\right)\left(d v_{d c} / d t\right), u=d_{n k}, f_{d}$ is an unknown, bounded external disturbance satisfying $\left.\left|f_{d}\right|<D, D\right\rangle 0$.

\section{Adaptive Backstepping Control}

The design of backstepping method consists of two steps. Firstly, a "virtual" controller is designed. Secondly, the real backstepping controller is derived. The detailed procedure with respect to the backstepping method is introduced as follows.

Step 1. The ideal current is denoted as $y_{d}$ with continuous second-order derivatives. The tracking error is

$$
e_{1}=x_{1}-y_{d}
$$

Then,

$$
\dot{e}_{1}=\dot{x}_{1}-\dot{y}_{d}=x_{2}-\dot{y}_{d} \text {. }
$$

The virtual control is designed as

$$
\alpha_{1}=-c_{1} e_{1}+\dot{y}_{d}
$$

where $c_{1}>0$.

Define current tracking error as

$$
e_{2}=x_{2}-\alpha_{1}
$$

We choose the first Lyapunov function candidate as

$$
V_{1}=\frac{1}{2} e_{1}^{2}
$$




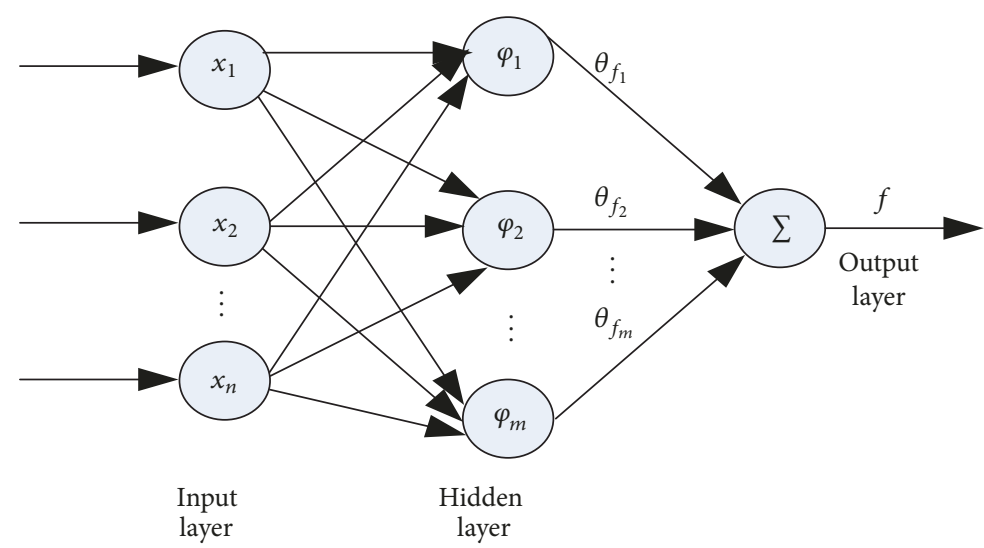

FIGURE 2: Neural network structure.

Differentiating (16) yields

$$
\begin{aligned}
\dot{V}_{1} & =e_{1}\left(x_{2}-\dot{y}_{d}\right)=e_{1}\left(e_{2}+\alpha_{1}-\dot{y}_{d}\right) \\
& =e_{1}\left(e_{2}-c_{1} e_{1}+\dot{y}_{d}-\dot{y}_{d}\right)=-c_{1} e_{1}^{2}+e_{1} e_{2} .
\end{aligned}
$$

If $e_{2}=0$, then $\dot{V}_{1}=-c_{1} e_{1}^{2} \leq 0$. So we need to take the second step.

Step 2. From (15), we can get

$$
\begin{aligned}
\dot{e}_{2} & =\dot{x}_{2}-\dot{\alpha}_{1}=f(x)+b u-\dot{\alpha}_{1} \\
& =f(x)+b u-\ddot{y}_{d}+c_{1} \dot{e}_{1} .
\end{aligned}
$$

The second Lyapunov function is selected as

$$
V_{2}=V_{1}+\frac{1}{2} e_{2}^{2}
$$

and the derivative of $V_{2}$ is

$$
\dot{V}_{2}=-c_{1} e_{1}^{2}+e_{1} e_{2}+e_{2}\left[f(x)+b u-\ddot{y}_{d}+c_{1} \dot{e}_{1}\right] .
$$

To make $\dot{V}_{2} \leq 0$, backstepping controller is proposed as

$$
u=\frac{1}{b}\left[-f(x)+\ddot{y}_{d}-c_{1} \dot{e}_{1}-c_{2} e_{2}-e_{1}\right]
$$

where $c_{2}>0$.

Then,

$$
\dot{V}_{2}=-c_{1} e_{1}^{2}-c_{2} e_{2}^{2} \leq 0 .
$$

Based on Lyapunov stability theory, the asymptotic stability is ensured.

\section{Adaptive Neural Backstepping Controller}

Figure 2 is a block diagram of a three-layer RBF neural network structure, which mainly includes input layer, hidden layer, and output layer. The hidden layer maps the signal from the input space to a higher-dimensional space, and the output layer performs a weighted summation operation to generate an RBF network output value.
RBF network can approach any nonlinear function over a compact set with arbitrary precision. The block diagram of adaptive neural backstepping system is designed in Figure 3.

Since $f(x)$ in (11) is unknown, a RBF neural estimator is used to approach $f(x)$. Because there is minimum approximation error in the neural netwro ksystem, in order to guarantee the stability of the closed-loop system, a compensation controller $u_{s}$ is added to the controller (21). The detailed reason why the compensation controller is incorporated in the control will be discussed in the next derivation steps. As shown in Figure 3, based on (21), the new controller is proposed as

$$
u=\frac{1}{b}\left[-\widehat{f}(x)+\ddot{y}_{d}-c_{1} \dot{e}_{1}-c_{2} e_{2}-e_{1}-u_{s}\right]
$$

where

$$
\widehat{f}(x)=\widehat{f}\left(x \theta_{f}\right)=\theta_{f}^{T} \varphi(x) .
$$

In (27), radial basis $\varphi(x)=\exp \left(-\left\|x-k_{j}\right\|^{2} / 2 b_{j}{ }^{2}\right), j=$ $1,2, \ldots, m, b_{j}$ is the base width of the node $j, k_{j}$ is the centric vector of the node $j, \theta_{f}$ denotes the weight of the neural structure:

$$
\dot{\theta}_{f}=r e_{2} \varphi(x),
$$

where $r$ is a positive constant.

Define optimal parameter

$$
\theta_{f}{ }^{*}=\arg \min _{\theta_{f} \in \Omega_{f}}\left[\sup \left|\widehat{f}\left(\begin{array}{c}
x \theta_{f} \\
x \in R^{n}
\end{array}\right)-f(x)\right|\right],
$$

where $\Omega_{f}$ is an assemble for $\theta_{f}$.

Define minimum approximation error:

$$
\omega=f(x)-\widehat{f}\left(x \theta_{f}^{*}\right),
$$

where $|\omega| \leq \omega_{\max }$. 
TABLE 1: Simulation Parameters.

\begin{tabular}{lr}
\hline neural output nodes, hidden layer neuron, hidden nodes & $3,6,3$ \\
\hline centric vectors $k$, base width $b$ & $-3: 1: 2,1$ \\
\hline adaptive gain $r$ & 1000 \\
\hline parameters of backstepping $c_{1}, c_{2}, c_{3}$ & $10000,10000,10000$ \\
\hline$u_{s}$ & 2.5 \\
\hline PI control parameters $K_{P}, K_{i}$ & $0.05,0.01$ \\
\hline
\end{tabular}

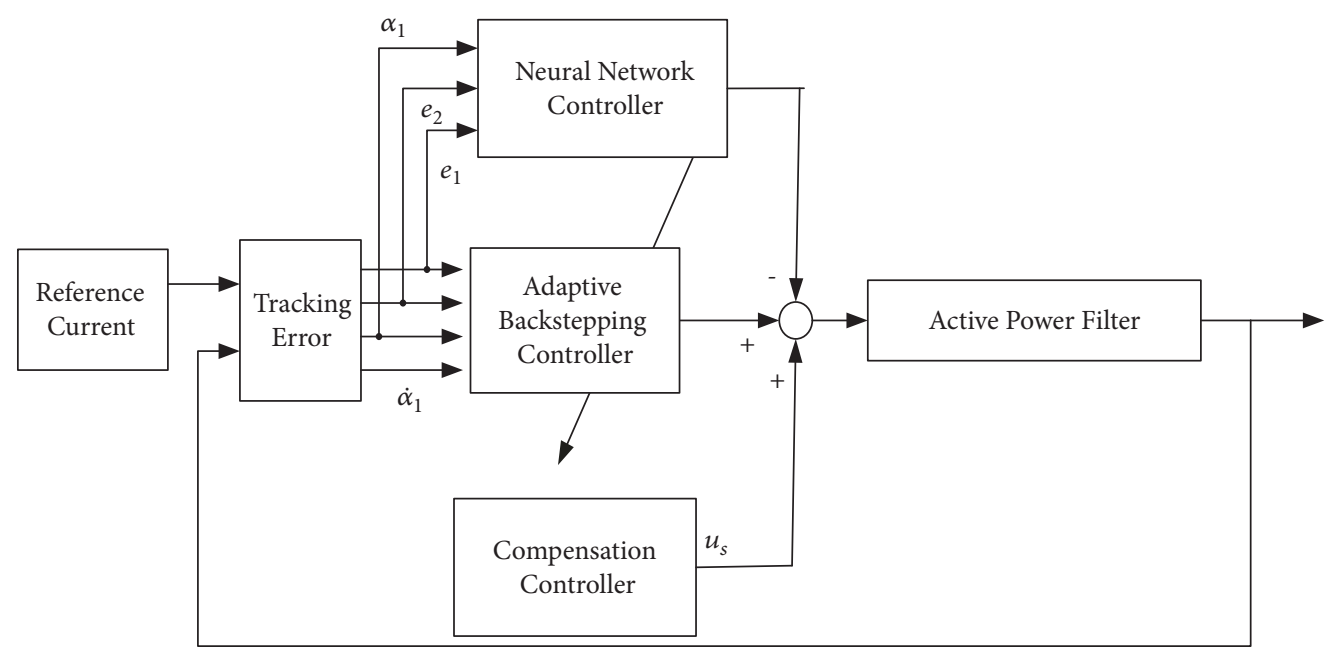

FIGURE 3: Control structure of adaptive neural backstepping controller.

Define the third Lyapunov function candidate as

$$
V_{3}=V_{2}+\frac{1}{2 r} \varphi_{f}^{T} \varphi_{f}
$$

where $\varphi_{f}=\theta_{f}^{*}-\theta_{f}$.

The derivative of $V_{3}$ is calculated as

$$
\begin{aligned}
\dot{V}_{3}= & \dot{V}_{2}+\frac{1}{r} \varphi_{f}^{T} \dot{\varphi}_{f} \\
= & -c_{1} e_{1}^{2}+e_{1} e_{2}+e_{2}\left[f(x)+b u-\ddot{y}_{d}+c_{1} \dot{e}_{1}\right] \\
& +\frac{1}{r} \varphi_{f}^{T} \dot{\varphi}_{f} \\
= & -c_{1} e_{1}^{2}-c_{2} e_{2}^{2}+e_{2}\left[\widehat{f}\left(x \theta_{f}^{*}\right)-\widehat{f}(x)+\omega-u_{s}\right] \\
& +\frac{1}{r} \varphi_{f}^{T} \dot{\varphi}_{f} \\
= & -c_{1} e_{1}^{2}-c_{2} e_{2}^{2}+e_{2}\left[\varphi_{f}^{T} \varphi(x)+\omega-u_{s}\right]+\frac{1}{r} \varphi_{f}^{T} \dot{\varphi}_{f} \\
= & -c_{1} e_{1}^{2}-c_{2} e_{2}^{2}+\frac{1}{r} \varphi_{f}^{T}\left(r e_{2} \varphi(x)+\dot{\varphi}_{f}\right) \\
& +e_{2}\left(\omega-u_{s}\right),
\end{aligned}
$$

where $\dot{\varphi}_{f}=-\dot{\theta}_{f}$.
Substituting (25) into (29) yields

$$
\begin{aligned}
\dot{V}_{3} & =-c_{1} e_{1}^{2}-c_{2} e_{2}^{2}+e_{2}\left(\omega-u_{s}\right) \\
& \leq-c_{1} e_{1}^{2}-c_{2} e_{2}^{2}+e_{2}\left(\sup _{t \geq 0}|\omega|-u_{s}\right) .
\end{aligned}
$$

If we choose $u_{s} \geq \sup _{t \geq 0}|\omega|$, then

$$
\dot{V}_{3} \leq-c_{1} e_{1}^{2}-c_{2} e_{2}^{2} \leq 0 .
$$

This implies that $\dot{V}$ is negative semidefinite, and $e_{1}, e_{2}$, and $\varphi_{f}$ are bounded signals. From Barbalat's Lemma [25], that is, if a scalar function $g(t)$ is uniformly continuous such that $\lim _{t \rightarrow \infty} \int_{0}^{t} g(\tau) d \tau$ exists and is finite, then $\lim _{t \rightarrow \infty} g(t)=0$. Then, we can conclude $\lim _{t \rightarrow \infty} e_{1}(t)=0, \lim _{t \rightarrow \infty} e_{2}(t)=0$.

\section{Simulation Discussion}

Simulation studies using Matlab/Simulink and SimPower Toolbox are conducted to verify the performance of the proposed controller. The APF controller starts to work at 0.05 $\mathrm{s}$, and load shock is introduced at $0.12 \mathrm{~s}$. Table 1 shows the simulation parameters adopted in the APF control system: The parameters of APF: inductance $L$ on the AC side is selected $L=5 \mathrm{mH}$; capacitor voltage $v_{d c}$ on the DC side is $v_{d c}=100 \mathrm{uF}$.

Figures 4 and 5 show the source current and harmonics spectrum, giving that $\mathrm{A}$ phase current contains harmonic 


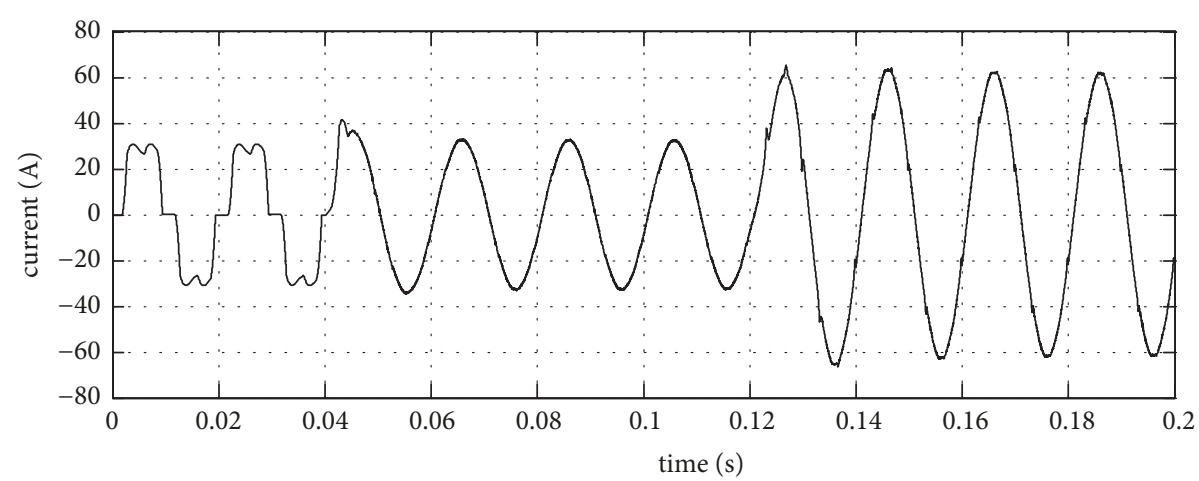

- A phase current

Figure 4: A phase current using backstepping control.

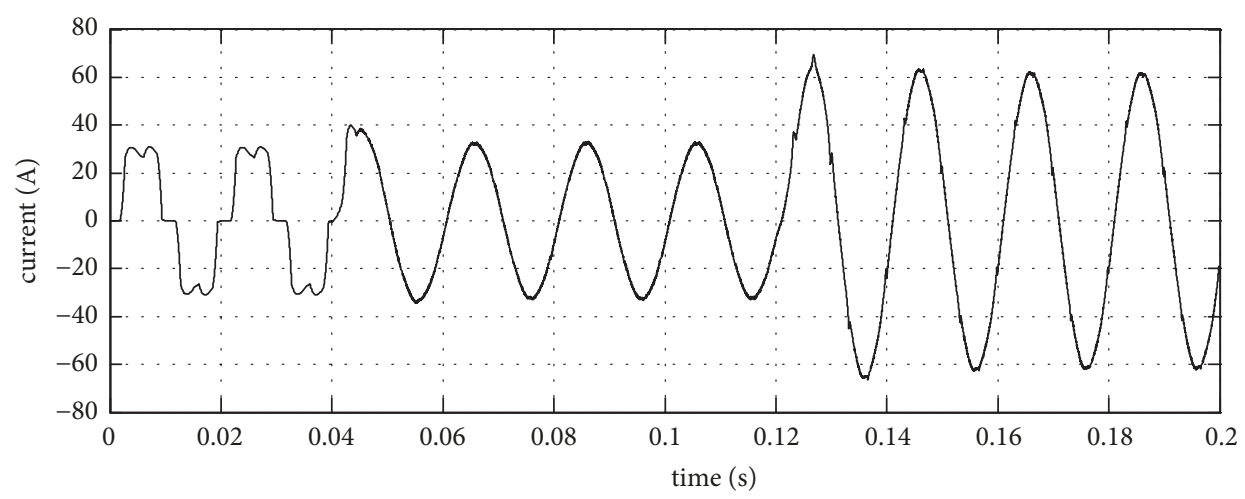

- A phase current

Figure 5: A phase current with the designed method.

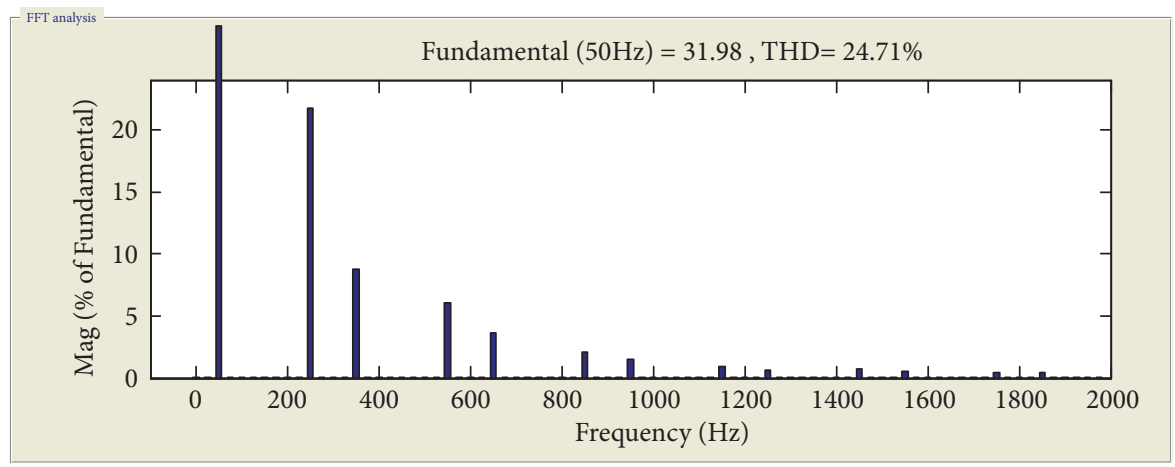

Figure 6: Source current harmonic graph when $t=0 \mathrm{~s}$.

whose THD value is $24.71 \%$. Figure 6 is the source current harmonic graph at the beginning. After $0.05 \mathrm{~s}$, APF begins to work to make the current close to sine wave in no more than $0.01 \mathrm{~s}$. The load shock is added at 0.12 . Figures 4,7 , and 9 plot the source current and harmonics spectrum using backstepping method, and Figures 5, 8, and 10 show the source current and harmonics spectrum using the proposed method. The source current is close to sine waveform after adaptive neural backstepping compensation even with load shock. The THD values are decreased to $2.96 \%$ and $3.81 \%$ with the backstepping method, whereas the THD values are decreased to $1.63 \%$ and $2.08 \%$ with the proposed method. The proposed method has better compensation property in the presence of the load shock than the backstepping control.

Figure 11 is the current compensation using the designed method where the tracking performance is well in the presence of nonlinear load shock. For the voltage control, we add the loads in a ladder-type increase. Specifically speaking, we add the same loads to the system at the time $0.1 \mathrm{~s}$ and $0.2 \mathrm{~s}$ to see the performance of the controlled system. PI controller is used in the voltage control. DC capacitor voltage is shown in Figure 12, indicating that it is in the range of the reference 


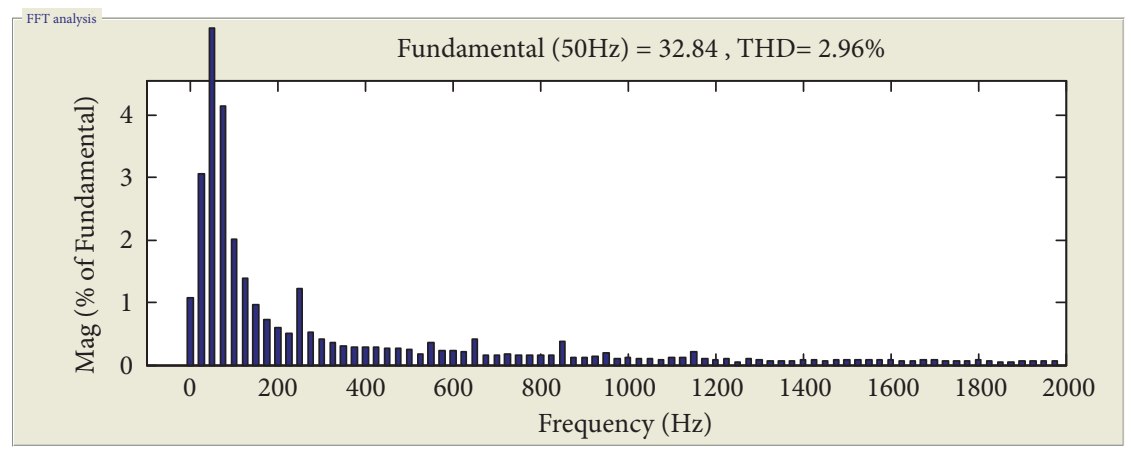

FIGURE 7: Source current harmonic graph when $t=0.05 \mathrm{~s}$ with the backstepping controller.

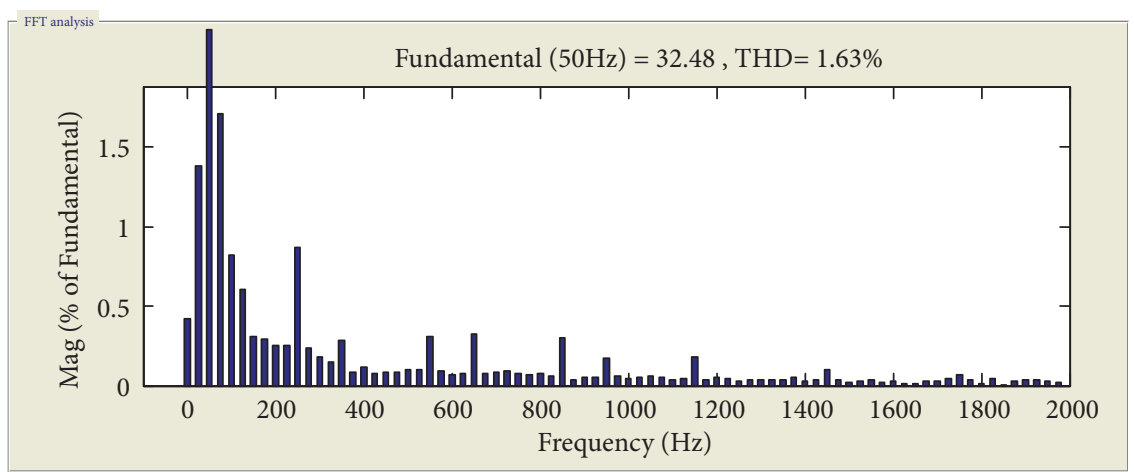

FIGURE 8: Source current harmonic analysis when $t=0.05 \mathrm{~s}$ with the designed controller.

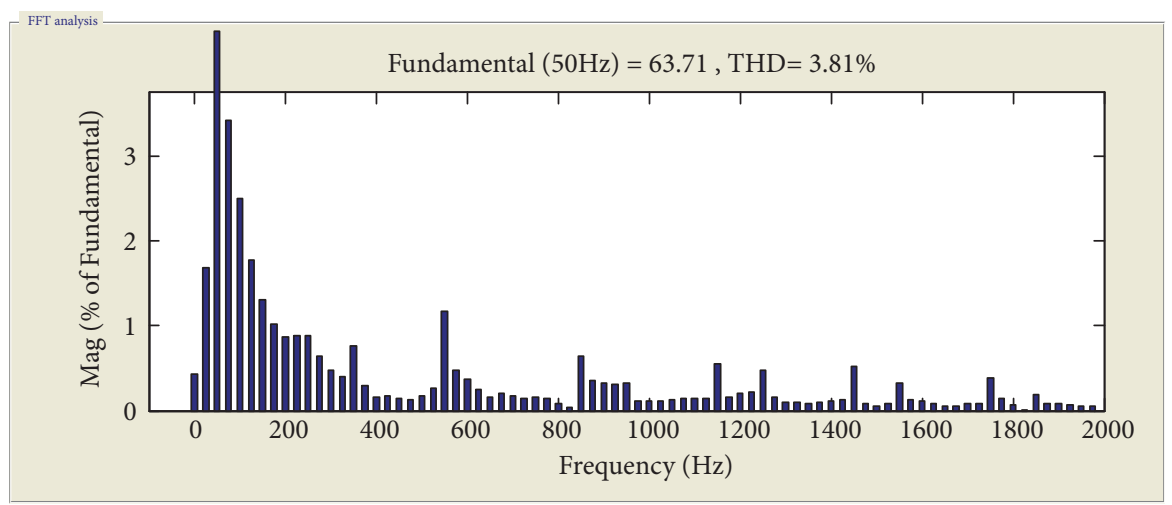

FIGURE 9: Source current harmonic when $t=0.13 s$ with the backstepping controller.

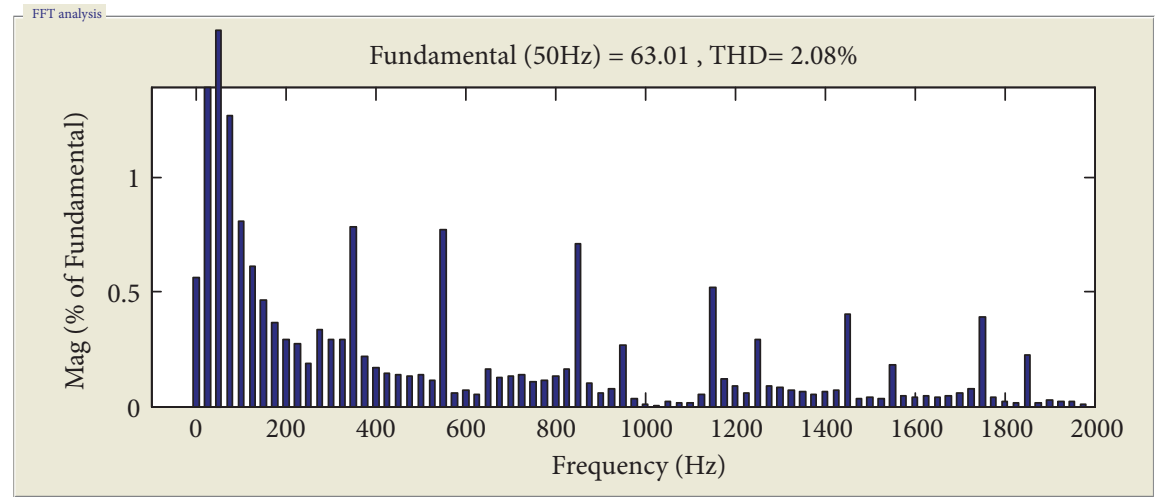

FIGURE 10: Source current harmonic graph when $t=0.13 \mathrm{~s}$ with the designed controller. 


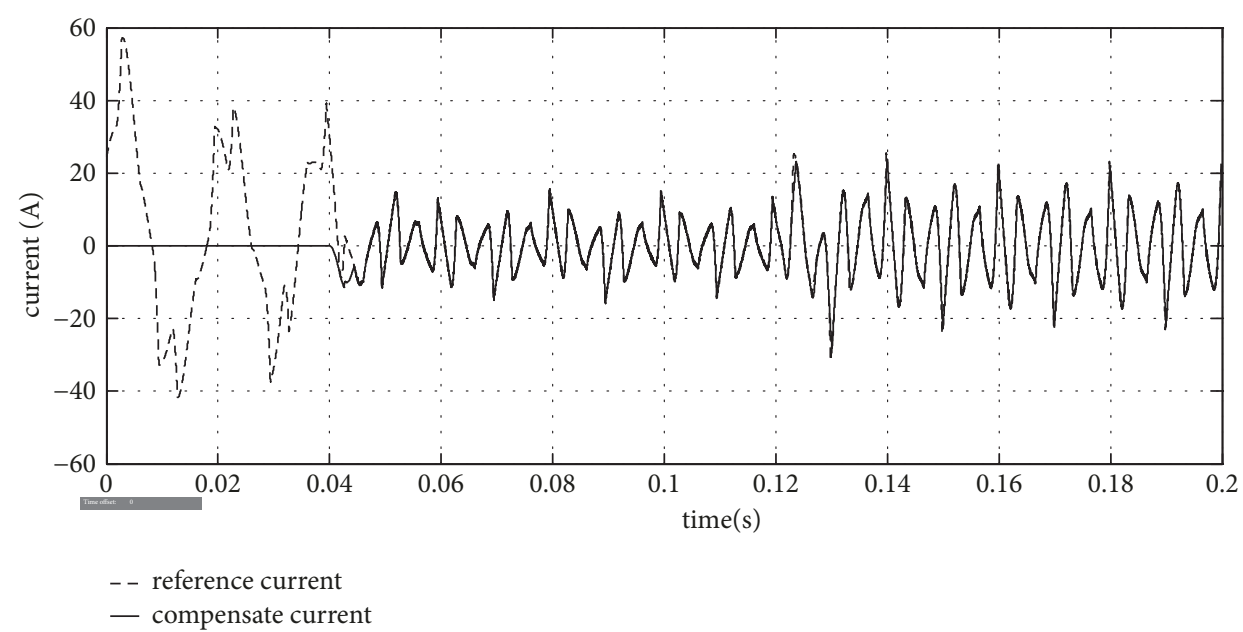

FIGURE 11: Instruction current and compensation current with the designed controller.

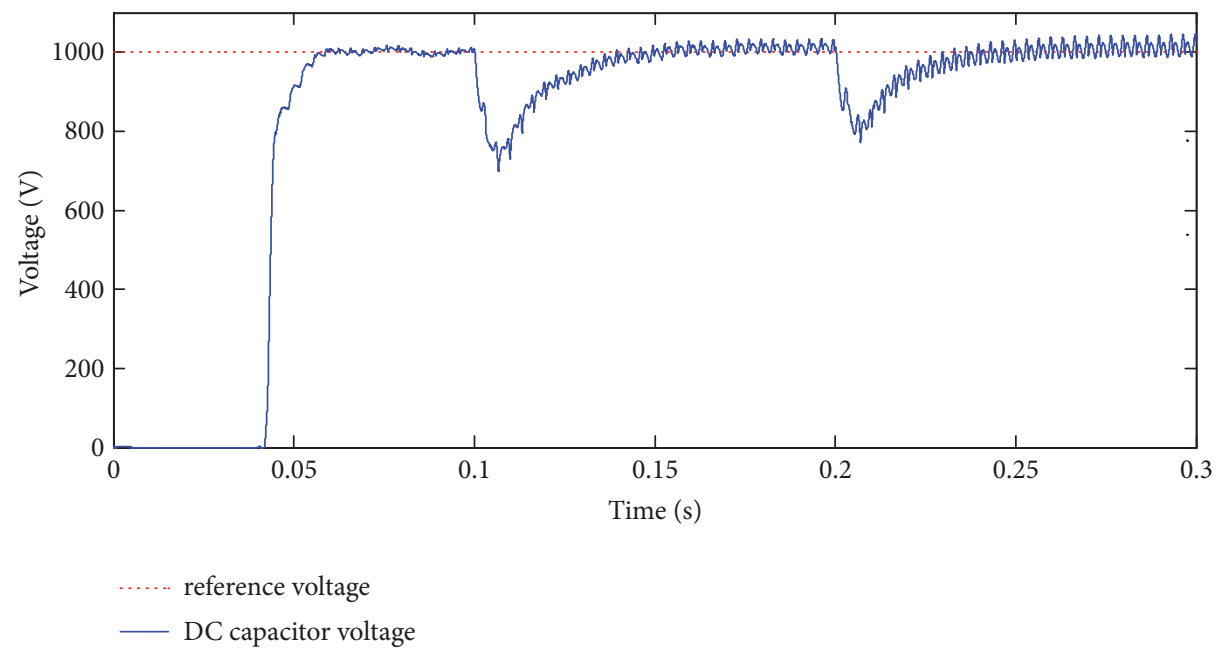

FIGURE 12: DC capacitor voltage with the designed controller.

voltage, and tends to be steady state quickly under the load shock.

\section{Conclusion}

An adaptive NN backstepping controller is designed for the harmonic suppression of a three-phase APF. A RBF NN controller is used to adaptively estimate and compensate the system nonlinearities, enhancing the robust performance. A compensation control $u_{s}$ is added to the controller to guarantee the stability. Simulation studies demonstrated that the proposed control strategy can reduce THD values effectively, improving the electric quality.

\section{Data Availability}

The data used to support the findings of this study are included within the article.

\section{Conflicts of Interest}

The authors declare that there are no conflicts of interest regarding the publication of this paper.

\section{Acknowledgments}

The authors thank the anonymous reviewers for their useful comments that improved the quality of the paper. This work is supported by National Science Foundation of China under Grant no. 61873085 and Natural Science Foundation of Jiangsu Province under Grant no. BK20171198. The Fundamental Research Funds for the Central Universities under Grant no. 2017B 20014.

\section{References}

[1] Y. Yue and Y. Chen, "Robust predictive dual-loop control method based on Lyapunov function stability and energy equilibrium though double-core processors for active power filter," 
International Journal of Electrical Power \& Energy Systems, vol. 89, pp. 69-81, 2017.

[2] S. D. Swain, P. K. Ray, and K. B. Mohanty, "Improvement of power quality using a robust hybrid series active power filter," IEEE Transactions on Power Electronics, vol. 32, no. 5, pp. 34903498, 2017.

[3] S. Hou and J. Fei, "Finite-time adaptive fuzzy-neural-network control of active power filter," IEEE Transactions on Power Electronics, pp. 1-1, 2019.

[4] J. Fei and T. Wang, "Adaptive fuzzy-neural-network based on Rbfnn control for active power filter," International Journal of Machine Learning and Cybernetics, vol. 6, pp. 1-12, 2018.

[5] Y. Chu, J. Fei, and S. Hou, "Dynamic global proportional integral derivative sliding mode control using radial basis function neural compensator for three-phase active power filter," Transactions of the Institute of Measurement and Control, vol. 40, no. 12, pp. 3549-3559, 2018.

[6] G. Carpinelli, D. Proto, and A. Russo, "Optimal planning of active power filters in a distribution system using trade-off/risk method," IEEE Transactions on Power Delivery, vol. 32, no. 2, pp. 841-851, 2017.

[7] W. U. Tareen, S. Mekhilef, M. Seyedmahmoudian, and B. Horan, "Active power filter (APF) for mitigation of power quality issues in grid integration of wind and photovoltaic energy conversion system," Renewable \& Sustainable Energy Reviews, vol. 70, pp. 635-655, 2017.

[8] J. Fei and H. Ding, "Adaptive sliding mode control of dynamic system using RBF neural network," Nonlinear Dynamics, vol. 70, no. 2, pp. 1563-1573, 2012.

[9] Y. Zhu and J. Fei, "Disturbance observer based fuzzy sliding mode control of pv grid connected inverter," IEEE Access, vol. 6, pp. 21202-21211, 2018.

[10] Y.-J. Liu, M. Gong, S. Tong, C. L. P. Chen, and D.-J. Li, “Adaptive fuzzy output feedback control for a class of nonlinear systems with full state constraints," IEEE Transactions on Fuzzy Systems, vol. 26, no. 5, pp. 2607-2617, 2018.

[11] H. Wu and Z. Wang, "Observer-based hinfty sampled-data fuzzy control for a class of nonlinear parabolic pde systems," IEEE Transactions on Fuzzy Systems, vol. 26, no. 2, pp. 454-473, 2018.

[12] Y. Li and S. Tong, "Adaptive neural networks prescribed performance control design for switched interconnected uncertain nonlinear systems," IEEE Transactions on Neural Networks and Learning Systems, vol. 29, no. 7, pp. 3059-3068, 2018.

[13] Z. Peng, D. Wang, and J. Wang, "Predictor-based neural dynamic surface control for uncertain nonlinear systems in strict-feedback form," IEEE Transactions on Neural Networks and Learning Systems, vol. 28, no. 9, pp. 2156-2167, 2017.

[14] H. Wang, H. R. Karimi, P. X. Liu, and H. Yang, "Adaptive neural control of nonlinear systems with unknown control directions and input dead-zone," IEEE Transactions on Systems, Man, and Cybernetics Systems, vol. 48, no. 11, pp. 1897-1907, 2018.

[15] H. Wang, P. X. Liu, and B. Niu, "Robust fuzzy adaptive tracking control for nonaffine stochastic nonlinear switching systems," IEEE Transactions on Cybernetics, vol. 48, no. 8, pp. 2462-2471, 2018.

[16] H. Wang, P. X. Liu, S. Li, and D. Wang, "Adaptive neural outputfeedback control for a class of nonlower triangular nonlinear systems with unmodeled dynamics," IEEE Transactions on Neural Networks and Learning Systems, vol. 29, no. 8, pp. 36583668, 2018.
[17] B. Xu, D. Yang, Z. Shi, Y. Pan, B. Chen, and F. Sun, "Online recorded data-based composite neural control of strict-feedback systems with application to hypersonic flight dynamics," IEEE Transactions on Neural Networks and Learning Systems, vol. 29, no. 8, pp. 3839-3849, 2018.

[18] C. S. Chen, "Dynamic structure neural-fuzzy networks for robust adaptive control of robot manipulators," IEEE Transactions on Industrial Electronics, vol. 55, no. 9, pp. 3402-3414, 2008.

[19] R.-J. Wai and R. Muthusamy, "Fuzzy-neural-network inherited sliding-mode control for robot manipulator including actuator dynamics," IEEE Transactions on Neural Networks and Learning Systems, vol. 24, no. 2, pp. 274-287, 2013.

[20] Y. Fang, J. Fei, and T. Hu, "Adaptive backstepping fuzzy sliding mode vibration control of flexible structure," Journal of Low Frequency Noise, Vibration and Active Control, vol. 37, no. 4, pp. 1079-1096, 2018.

[21] Y. Li, S. Qiang, X. Zhuang, and O. Kaynak, "Robust and adaptive backstepping control for nonlinear systems using RBF neural networks," IEEE Transactions on Neural Networks and Learning Systems, vol. 15, no. 3, pp. 693-701, 2004.

[22] Y. Fang, J. Fei, and Di. Cao, "Adaptive fuzzy-neural fractionalorder current control of active power filter with finite-time sliding controller," International Journal of Fuzzy System, 2019.

[23] J. Fei and Z. Wang, "An adaptive neural network control of active power filter," International Journal of Advanced Robotic Systems, vol. 10, pp. 1-7, 2013.

[24] Y. Fang, J. Fei, and Z. Wang, "Adaptive neural backstepping control strategy of three-phase active power filter," in Proceedings of the European Control Conference 2015, Linz, Austria, July 2015.

[25] P. A. Ioannou and J. Sun, Robust Adaptive Control, PrenticeHall, Upper Saddle River, NJ, USA, 1996. 


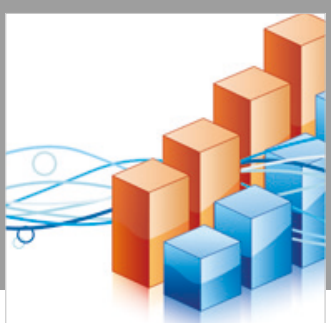

Advances in

Operations Research

\section{-n-m}
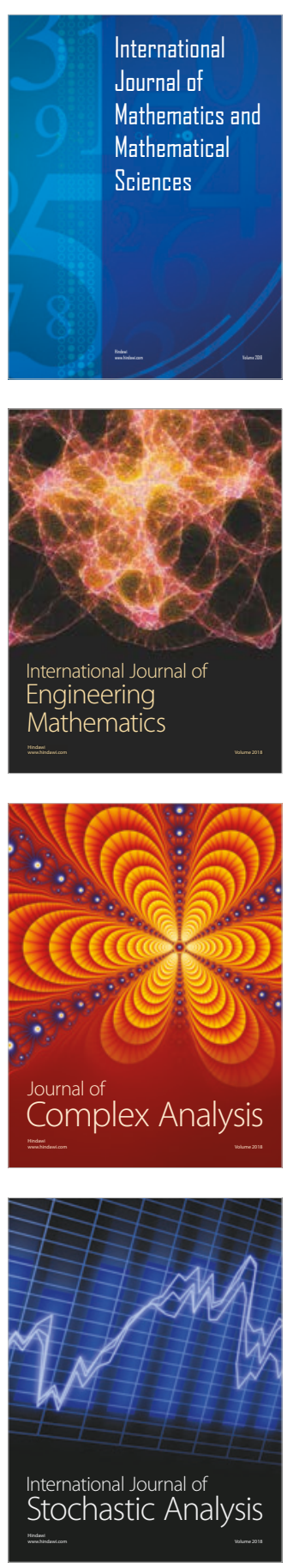
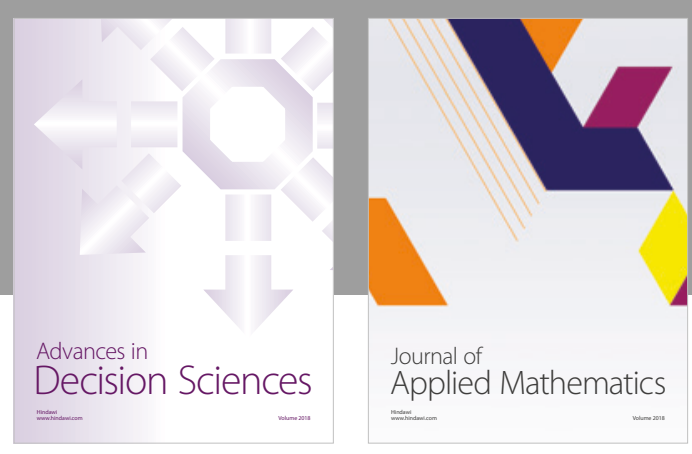

Journal of

Applied Mathematics
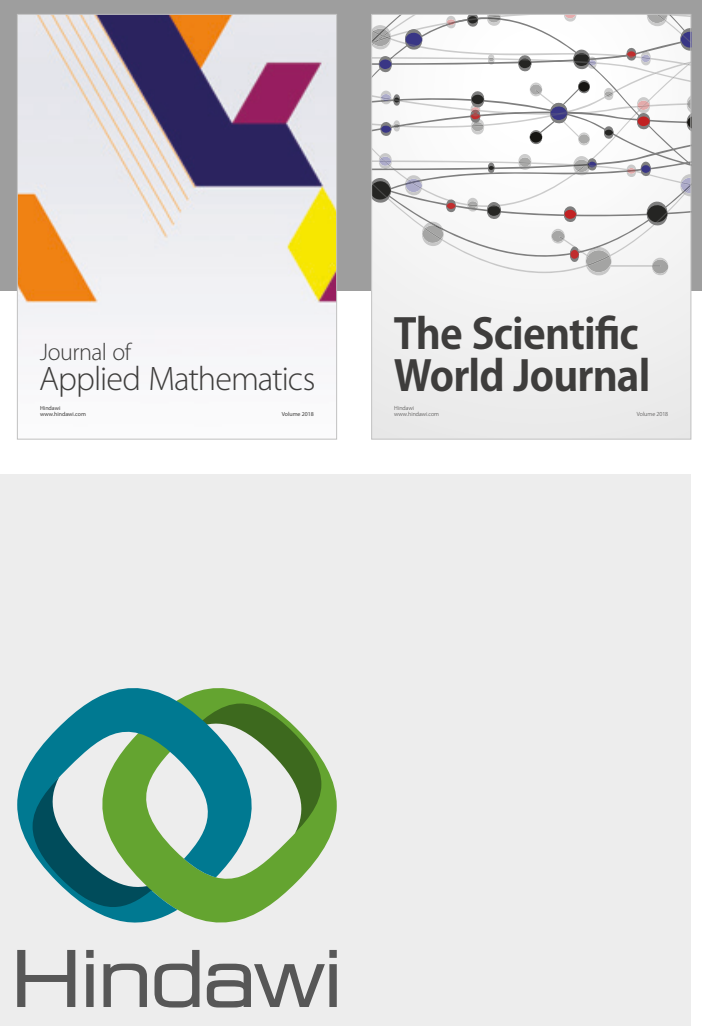

Submit your manuscripts at

www.hindawi.com

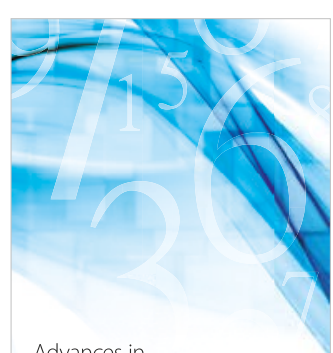

Advances in
Numerical Analysis
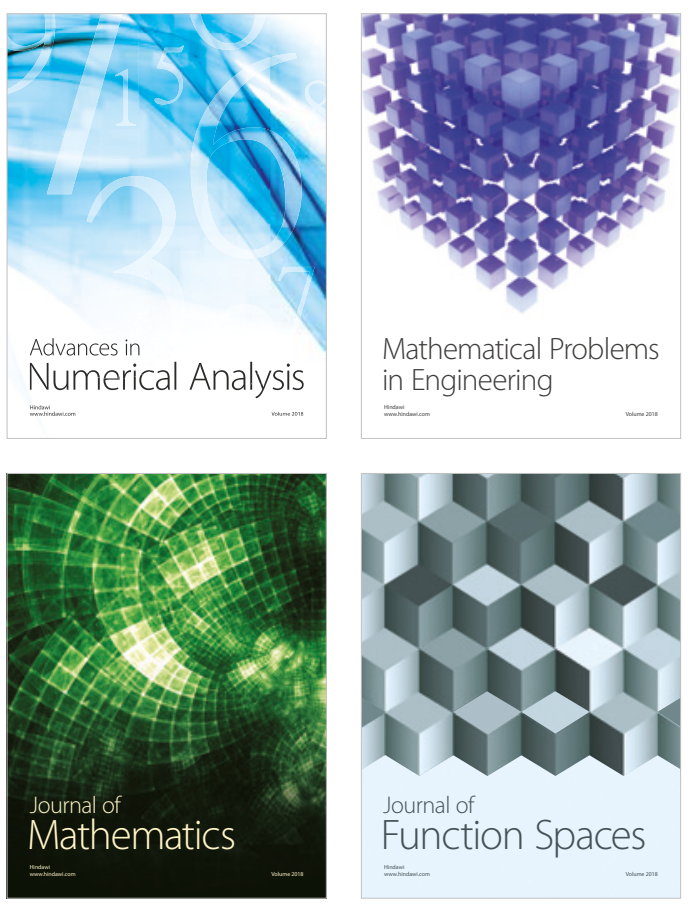

Mathematical Problems in Engineering

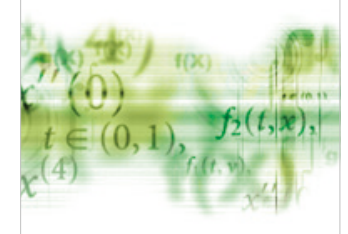

International Journal of

Differential Equations

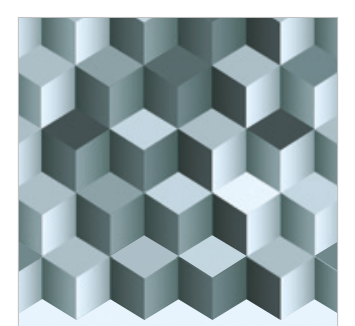

Journal of

Function Spaces

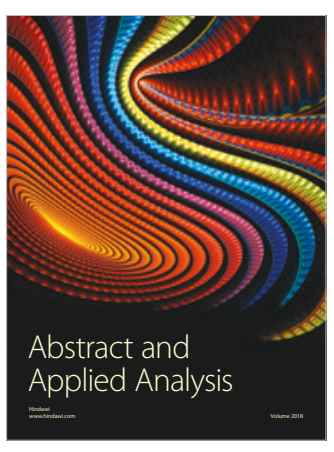

The Scientific

World Journal

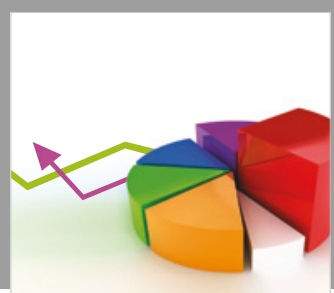

Journal of

Probability and Statistics
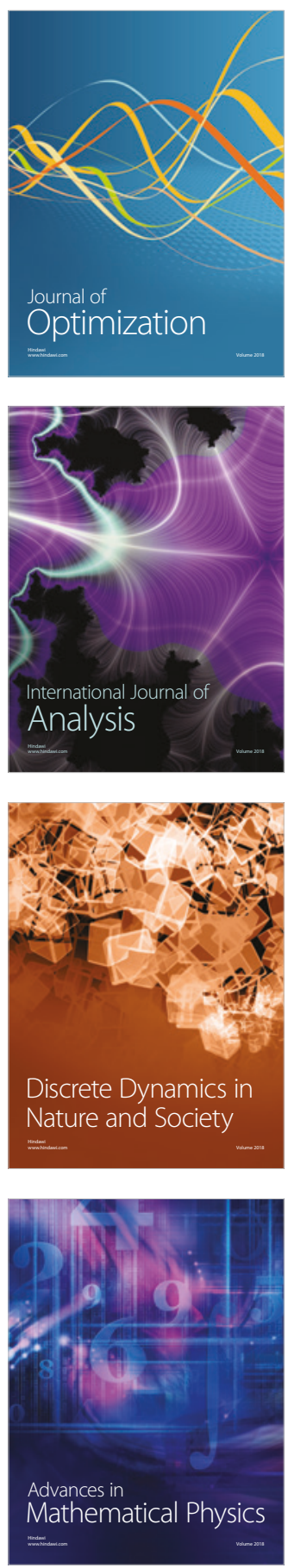